\title{
Analysis of Port-Based Discharge Water Treatment of Ships, Case Study: PT. TPS
}

\author{
Taufik Fajar Nugroho $^{1}$, Alam Baheramsyah ${ }^{2}$, Nurkhairana Aryanti Trikurnia ${ }^{3}$
}

(Received: 25 February 2019 / Revised: 21 March 2019 / Accepted: 24 March 2019)

\begin{abstract}
In Indonesia, highly concentrated goods movement are reported in Java and Sumatera which leads Tanjung Perak, Surabaya to become second largest ship terminal after Tanjung Priok, Jakarta. As the loading and unloading process is on call, any kinds of wastewater are continuously being discharged (sludge, oily sludge, blackwater, and greywater). All wastewater if continuously discharged without any proper treatment is harmful to both human and aquatic environment. Especially in Indonesia and northern part of Java island where marine tourism is growing but on the other hand, also the home of the largest ports. The purpose of this research is to design a fixed, compact discharge water treatment plant in one pilot international terminal. The capacity of each discharge water receiver and treatment is determined according to the ship's arrival data. Based on the data analysis, the capacity of the sludge receiver is $25 \mathrm{~m} 3 /$ day, oily bilge receiver for $200 \mathrm{~m} 3 /$ day, blackwater for $10 \mathrm{~m} 3 /$ day and greywater for $20 \mathrm{~m} 3 /$ day. Hereinafter, through the literature review of various kinds of wastewater treatment, a fixed and compact portbased discharge water treatment plant is designed by combining Membrane Bioreactor (MBR) for greywater, centrifugation for sludge, combination of ultrafiltration and reverse osmosis for oily bilge and Source Separation Sanitation (SSS) for blackwater where each effluent of the treatment can be used for one another. Furthermore, an initial cost of the designed port-based discharge water treatment plant is conducted, resulting in a total of IDR $22,487,086,876$. The payback period (PBP) of the plant is 4 years.
\end{abstract}

Keywords—port-based discharge water treatment, ship wastewater.

\section{INTRODUCTION}

M aritime sector is the busiest sector in the world, including the shipping industry, sea transportation and even mining activities such as fuel exploration. $90 \%$ of world trade is carried by the shipping industry and over 50,000 merchant ships are transporting any kind of cargo worldwide (International Chamber of Shipping, 2018). As for Indonesia, highly concentrated goods movement are reported in Java and Sumatera (National Development Planning Agency (BAPPENAS), 2013). This phenomenon leads to Tanjung Perak, Surabaya to become second largest ship terminal in Indonesia.

Tanjung Perak, Surabaya is not only dealing with domestic goods movement, but also one of the busiest port dealing with international goods trade in Indonesia. One of several international terminals in Tanjung Perak Surabaya, PT. TPS recorded that more than a thousand of international-sailing ships entered the terminal of TPS per 2017, loading and unloading for about tens of thousands container per month [1].

Taking this into account, as the loading and unloading process is on call, wastewater is continuously being discharged. There are five kinds of discharged wastewater coming from ship's hull: ballast water,

Taufik Fajar Nugroho., Departement of Marine Engineering, Institut Teknologi Sepuluh Nopember, Surabaya, 60111, Indonesia. E-mail: taufikfajar@ne.its.ac.id

Alam Baheramsyah., Departement of Marine Engineering, Institut Teknologi Sepuluh Nopember, Surabaya, 60111, Indonesia. E-mail: alam@its.ac.id

Nurkhairana Aryanti Trikurnia Hochschule Wismar, University of Applied Sciences Technology Business and Design, Wismar, Germany. E-mail: ranaaryanti@yahoo.com sludge, oily bilge water, greywater, and blackwater. Sludge is originated from fuel oil and lubricating oil separation activity and stored in sludge tank before discharging into the sea or onshore [2]-[3]. Bilgewater is originated from the puddle on bilge area, mainly in machinery space. Sewage which is divided into two categories: greywater and blackwater, originated from greywater and blackwater holding tank consisting of human feces and urines. Ballast water is used for keeping the ship's stability during loading and unloading the cargo. The illustration on Figure. 1 explains and differs discharged wastewater coming from ships.

All four kinds of wastewater discharged from ships, if directly and continuously discharged into the open sea, will harm both the aquatic and human environment. Especially in Indonesia as an archipelagic country which has the total water area of $6.315 .222 \mathrm{~km} 2,99.093 \mathrm{~km} 2$ long of coastline and a total of 13.466 islands. Furthermore, Indonesia has developed a future plan to grow its marine tourism, taking advantage of having the second longest coastline in the world. Figure 2. illustrates the marine tourism development of Indonesia.

In this research, the author proposes a preventive action to treat those wastewater discharged by the ships. To benefit both shipowners as a 'polluters' and local government to keep the aquatic environment clean, a pilot design of a compact, fixed water treatment plant is designed. 


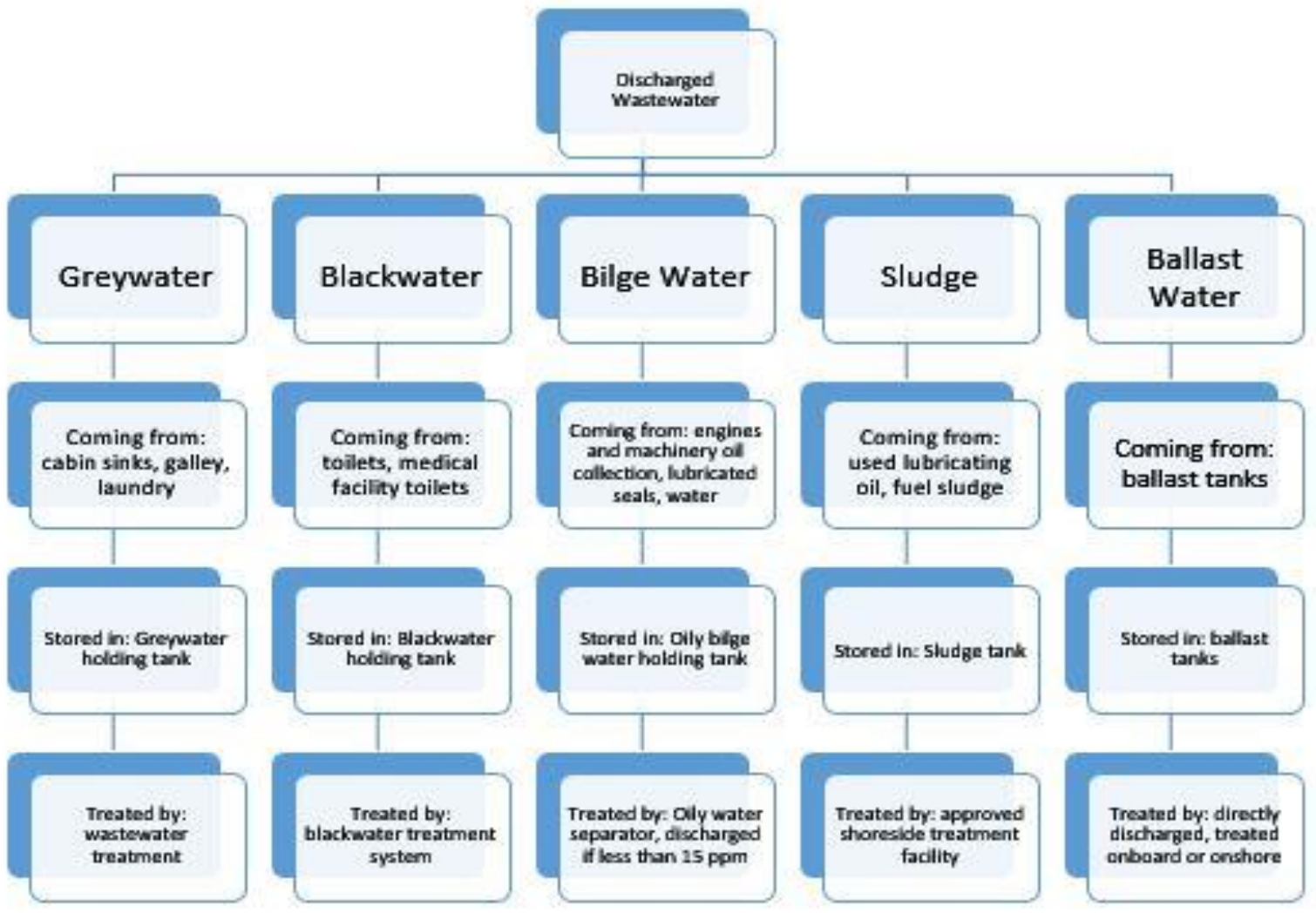

Figure.1. Kinds of discharge water coming from ships.

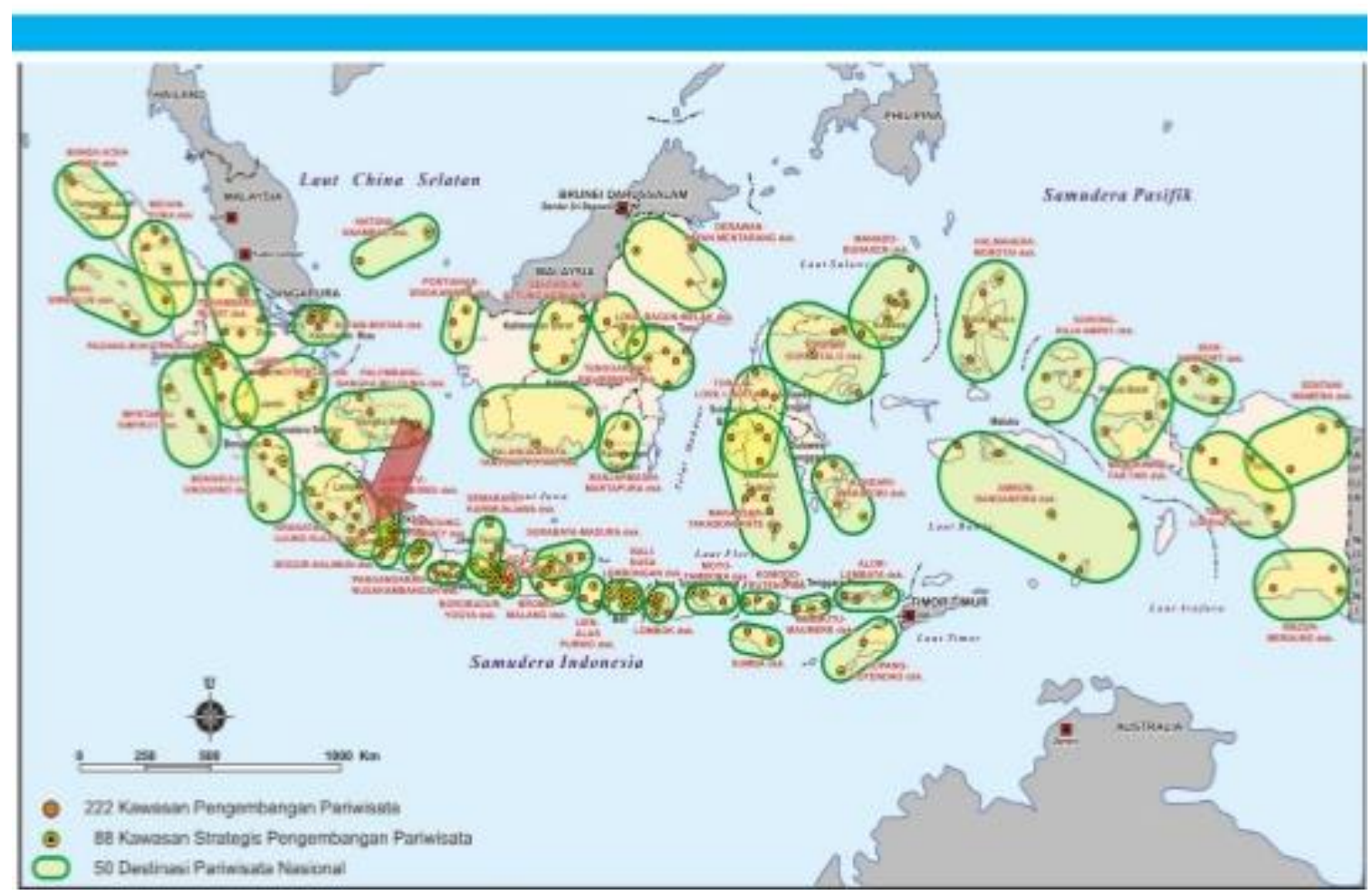

Figure 2.. Indonesia Marine Tourism Growth 


\section{METHOD}

\section{A. Problem Identification}

The problem identification starts from mindmapping what variables the author has to find at the end of this research as the answer to the problems which becomes the background of this research.

\section{B. Literature Review}

To support the background and solution of the problem, literature review concentrating on both technical and scientific approach relating to the topic is necessary before proceeding to the discussion.

\section{Data Collection}

The data needed is collected from ship arrival in a year. This research started from August 2018, therefore, the detailed data available from the terminal is from January until December 2017. The data obtained from the terminal consists of ship's names, port of origin, time berthing and time departure. These data need more information before being analyzed. Further information regarding the ships can be found in its classification society ship register.

D. Determination of discharge water receiver capacity

The determination of discharge water receiver capacity is necessary to be analyzed as the first step of designing overall port-based discharge water treatment plant. To do so, we need the information about how many $\mathrm{m} 3$ of discharge water is discharged per day. The determination of discharge water receiver capacity can be done in several steps:

1) Determine each ship's discharge water holding tank (sludge tank, oily bilge holding tank, greywater holding tank and black water holding tank).

2) Record the ship arrival per day

3) Determine the discharge water per day by totaling the volume of holding tanks of all ships which arrived on that day.

4) By completing the information of each day's discharge water volume for a whole year, average, maximum and minimum volume per day can be determined.

E. Determination of water treatment plant transportation

The meaning of this step is to determine the mode of transportation which will be used in handling the discharge water from ship to the plant. The portbased discharge water treatment plant is designed as a fixed platform and not portable because the aim of the design is to minimalize the waste and maximize the reusable materials after the treatment.

The mode of transportation is determined by each kind of discharge water's compiled volume. It is more economically efficient to use trucks to transport a little volume of discharge water and use pipelines to transport a large volume of discharge water.

F. Determination of water treatment system methods

Different kind of ship discharge water treatment cannot be treated by the same method. Therefore, the different treatment method is reviewed for a different kind of discharge water. The treatment system which produces the least cannot-be-reused effluent is chosen. The treatment system was chosen also considers the capacity of the volume. For example, the volume of oily bilge collected in container terminal is not as large as collected in tanker terminal. Thus, several methods of treating oily bilge water in tanker terminal are not economically effective to be used in a container terminal.

$G$. Designing the overall treatment plant

The overall design of the discharge water treatment plant combines all chosen discharge water treatment. Some product of one treatment may be used in other treatment or used in another unit. For example, the reusable water from greywater treatment plant can be used for water the plants or filling the office's daily need of toilet flushing.

H. Economic analysis of port-based water treatment plant

The economic analysis consists of BOQ (Bill of Quantity) which can be determined by totaling the overall system's main equipment and transportation modes and investment evaluation. In BOQ, however, plant building cost is excluded from the detail list in this research and be put in estimation percentage. As for investment evaluation, this research uses PBP (Payback period).

I. Conclusion

The conclusion of this paper includes the determined receiving volume of the plant, the overall design of the plant and economic analysis of the plant.

\section{RESULTS AND DISCUSSION}

\section{A. Determining adequate sludge receiver}

Before determining the most suitable method of sludge treatment which will be discussed in IV.5, the adequate capacity of the sludge receiver has to be calculated first according to ship arrival per day. The approximate sludge volume discharged can be known from ship arrival data. However, since the raw data does not provide the actual sludge volume discharged, several steps have to be taken in order to determine the volume. The first is completing the ship's principal dimension.

For ships which do not carry ballast water in oil fuel tanks, the minimum sludge tank capacity (V1) should be calculated by the following formula:

$$
\begin{aligned}
& V_{1}=K_{1} C D \\
& V_{1}=0.01 \times 41.388 \mathrm{~m}^{3} \times 4 \text { days } \\
& V_{1}=2.15 \mathrm{~m}^{3}
\end{aligned}
$$

Where $K_{1}$ is equal to 0.01 for ships where heavy fuel oil is purified for main engine use, or 0.005 for ships using diesel oil or heavy fuel oil which does not require purification before use, $\mathrm{C}$ is daily fuel consumption $\left(\mathrm{m}^{3}\right)$ and $\mathrm{D}$ is the maximum period of voyage between ports where sludge can be discharged ashore (days). In the absence of precise 
data, a figure of 30 days should be used. D can be known from the period of the voyage recorded.

1) Average volume per day: $17.15 \mathrm{~m}^{3}$

2) Maximum volume per day: $52.7 \mathrm{~m}^{3}$

3) Minimum volume per day: $1.895 \mathrm{~m}^{3}$

B. Determining the adequate capacity of oily bilge receiver

The capacity of adequate oily bilge receiver should be determined before designing the complete discharge water treatment system. The oily bilge water discharged can be known by determining the capacity of oily bilge water holding tank of each ship as dictated by Table.1. However, the oily bilge is frequently being treated onboard ship before discharging and it has a large volume. The oily bilge receiver can be studied further after determining which the average, maximum and minimum oily bilge volume discharged per day.

1) Average volume per day: $201.65 \mathrm{~m}^{3}$

2) Maximum volume per day: $442 \mathrm{~m}^{3}$

3) Minimum volume per day: $42.36 \mathrm{~m}^{3}$

C. Determining the adequate capacity of blackwater receiver

According to the ship arrival data and local minimum safe manning regulations, 4 ships out of 150 are manned by 20 crews and the rest are manned by 21 crews. Therefore, there are only small differences between the 21-crews manned and 20crews manned ships, resulting in the average blackwater holding tank capacity of $1.2 \mathrm{~m} 3$. The formula of this capacity is:

\section{$\mathrm{V}\left(\mathrm{m}^{3}\right)=\underline{3 \text { days } \times 20 \mathrm{~kg} \times \text { number of crew }}$

$$
1.025
$$

Based on the ship arrival data, the most frequent number of the ship arriving in one day is 5 ships. Thus the maximum of blackwater discharged per day is $6.15 \mathrm{~m} 3$. The average of blackwater volume discharged is $3.37 \mathrm{~m} 3$ while the minimum is 1.23 $\mathrm{m} 3$.

D. Determining the adequate capacity of greywater receiver

The adequate capacity of greywater treatment receiver can be determined by the volume of greywater holding tank of each ship calculated between the time off right before entering Indonesian water until the ship has arrived safely at the port and is ready to discharge the greywater. For this arrangement, the period of the voyage is estimated to be 3 days. The greywater holding tank capacity can be calculated by the following formula:

$$
\mathrm{V}\left(\mathrm{m}^{3}\right)=\frac{3 \text { days } \times 55 \mathrm{~kg} \times \text { number of crew }}{1.025}
$$

The adequate capacity of greywater treatment receiver can be determined by the maximum volume of greywater discharge per day which is $16.9 \mathrm{~m} 3$. The average of greywater volume discharged per day is $9.27 \mathrm{~m} 3$ while the minimum is $3.38 \mathrm{~m} 3$.

E. Design of discharge water treatment plant

According to the literature review done by the author, the combination of various treatment of each kind of discharge water consist of centrifugation method for sludge, oily sludge is treated by ultrafiltration and reverse osmosis, greywater is treated by Membrane Bioreactor (MBR) and blackwater is treated by SSS (Source Separation Sanitation).

Centrifugation method using centrifuges to separate fluids based on their densities whether it is water, solids, oil, and pasty mixtures. First, sludge is inserted into pre-treatment tank, which is purposed to reduce its viscosity by adding solvents, demulsifying agent and steam for heating. Once the viscosity of the sludge is reduced, the less viscous sludge is pumped into the centrifuge. The centrifuge then separates oily mixtures, oily wastewater, and waste solids. The oil phase then purified further using a gravimetric separator to produce recovered oil and separate solids. The wastewater then goes into the wastewater treatment unit while waste solids will be sent to landfill [4].

The chosen design of oily bilge treatment is using ultrafiltration. The ultrafiltration method of treatment produces a water phase which is generally of acceptable quality for direct sewer discharge into the sea and an oil phase that can be incinerated. Reverse osmosis (RO) and activated carbon treatment will permit reuse of the treated water as process water. The maximum attainable oil concentration ranges from 25 to $65 \%$ oil.

According to a blackwater treatment research conducted on Secovlje Saltpans Natural Park, Slovenia, as remote tourist facilities, a simple design using peat filters, compost reactor, biofilters, and evaporation module can be used to minimize the discharge and reuse the solid fraction as additional $\mathrm{P}$ (phosphorous) for the agricultural purpose [5].

The chosen design of greywater is using membrane bio-reactor (MBR) since MBR is more economically reliable, compact and produce better-treated water quality. The specific energy consumption of MBR based IISc STP (Indian Institute of Science Sewage Treatment Plant) is higher than conventional CAS based STPs [6]. The MBR for domestic sewage wastewater is available commercially worldwide in a compact design (containerized).

The complete port-based discharge water treatment plant layout can be seen in Figure 3.

TABLE 1

CAPACITY OF OILY BILGE WATER HOLDING TANK BASED ON CLASS RULES

\begin{tabular}{lc}
\hline Main Engine Rating $(\mathbf{k W})$ & Capacity $\left(\mathbf{m}^{\mathbf{3}}\right)$ \\
\hline Up to 1,000 & 4 \\
\hline Above 1,000 up to 2,000 & $\mathrm{P} / 250$ \\
\hline Above 20,000 & $40+\mathrm{P} / 500$ \\
\hline
\end{tabular}


F. Expected installation cost of discharge water treatment plant \& payback period

The installation cost of port-based discharge water treatment is divided into two categories; the installation cost by the means of transportation and water treatment plant's main equipment cost. Some assumption is made in the absence of actual installation cost data.

The transfer of discharge water from ship to shore is conducted by the vessel to the receivers. In this case, the oily sludge and blackwater are received by trucks while the oily bilge and greywater are delivered to the discharge water treatment facilities by pipelines. The total transportation installation cost is IDR 5,856,040,711.2 or around USD 415,675.80.

The discharge water treatment plant consists of several main types of equipment which are needed to be supplied, whether it is being built on site or directly installed after imported. The list of main equipment needed by the discharge water treatment plant is shown in Table 2.

The payback period analysis is basically aiming to determine how long the period of time of an investment to be paid back in the time of break evenpoint $^{[8]}$. The investment plant using this method is called feasible economically if the value $\mathrm{k}$ is smaller or equal to $n(k>n)$, where $n$ is the investment time. Before determining the value of $\mathrm{k}$, the amount of annual benefit has to be analyzed first. To do so, the author uses some assumption as listed below:

1. The discharge water management fee is charged to the shipowner based on the ship's gross tonnage. The cost for the discharge water management is adopted from Patras Port Authority regarding fee \& rates for waste reception facilities. The annual gross revenue from the fee is estimated to be IDR $12,941,480,256$.

2. The installation cost of the plant is estimated to be $50 \%$ of the total main equipment investment, resulting in a total investment of IDR 33,730,630,314.

3. The operational cost is divided into two: handling crew salary and technical operational expenditure. The annual salary for 10 handling crews is estimated to be IDR $600,000,000$ and technical operational expenditure is estimated to be IDR 3,373,063,031. Total operational cost is estimated to be IDR 3,973,063,031.

4. The economic life (n) is estimated to be 10 years.

Payback period (PBP)

$=($ Total investment $) /(($ Annual gross revenue-annual operational cost))

$=($ IDR 33,730,630,314) $/(($ IDR $12,941,480,256-$ IDR $3,973,063,031)$ )

$=4$ years.

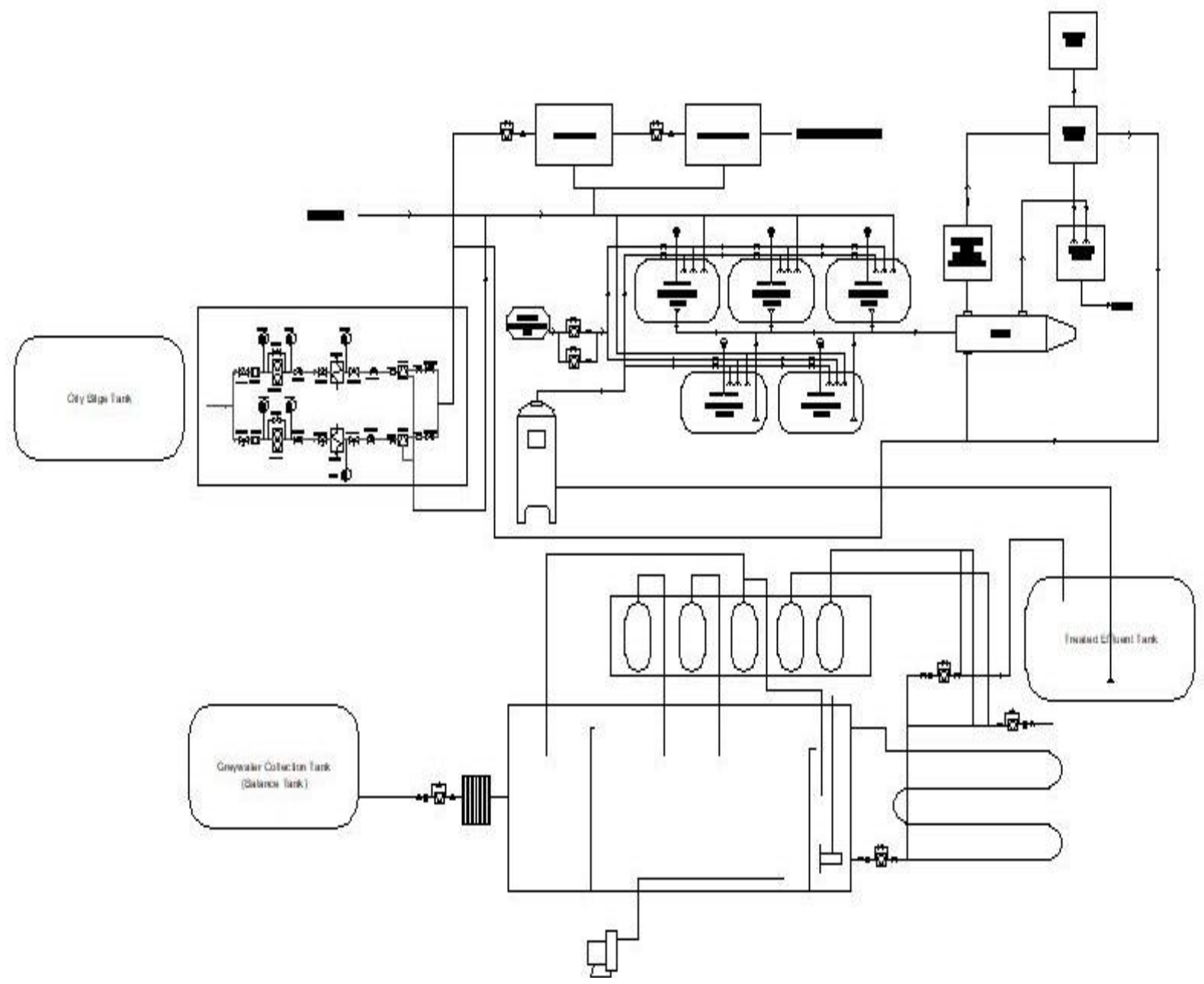

Figure 3. Overall discharge water treatment system workflow 
TABLE 2

LIST OF MAIN EQUIPMENT AND ITS PRICE

\begin{tabular}{|c|c|}
\hline Equipment Name & Price (estimated) \\
\hline $\begin{array}{l}\text { Sludge Treatment: } \\
\text { 1. Pre-Treatment Tank with mixer } \\
\text { 2. Demulsifying agent tank } \\
\text { 3. Demulsifying agent dosing pump } \\
\text { 4. Boiler } \\
\text { 5. Incinerator } \\
\text { 6. Centrifuge } \\
\text { 7. Contaminated recovered oil tank } \\
\text { 8. Waste solid collection tank } \\
\text { 9. Gravimetric separator } \\
\text { 10. Recovered oil tank }\end{array}$ & IDR 9,950,326,224 \\
\hline $\begin{array}{l}\text { Greywater Treatment: } \\
\text { 1. Compact MBR } \\
\text { 2. Treated Effluent tank } \\
\text { 3. Greywater collection tank }\end{array}$ & IDR $2,194,910,400$ \\
\hline $\begin{array}{l}\text { Oily Bilge Treatment: } \\
\text { 1. Oily bilge holding tank } \\
\text { 2. Separator } \\
\text { 3. Ultrafiltration pump } \\
\text { 4. Ultrafiltration module } \\
\text { 5. Reverse osmosis module }\end{array}$ & IDR $1,069,983,600$ \\
\hline $\begin{array}{l}\text { Blackwater Treatment: } \\
\text { 1. Collection tank } \\
\text { 2. Feed pump } \\
\text { 3. Tank for peat filters } \\
\text { 4. Tank for compost reactor } \\
\text { 5. Tank for biofilters } \\
\text { 6. Collection tank (Liquid Fractions) } \\
\text { 7. Evaporation tank } \\
\text { 8. Cascade dryer } \\
\text { 9. Solar Vacuum Collector (SVC) }\end{array}$ & IDR $223,999,200$ \\
\hline Total & IDR $13,439,219,424$ \\
\hline Estimated freight cost & IDR 9,800 \\
\hline Total payable before tax & IDR $13,439,229,224$ \\
\hline Import duty & IDR $1,343,922,922$ \\
\hline VAT (Value Added Tax) & IDR $1,478,315,215$ \\
\hline Income Tax & IDR $369,578,804$ \\
\hline Total & IDR $16,631,046,165$ \\
\hline
\end{tabular}

\section{CONCLUSION}

1. The adequate capacity of the sludge receiver can be determined by the largest compilation volume of sludge tanks of the ship doing its loading-unloading process at the terminal per day. The average compiled volume per day is $17.15 \mathrm{~m} 3$, maximum compiled volume per day is $52.7 \mathrm{~m} 3$, minimum compiled volume per day is $1.895 \mathrm{~m} 3$ while the largest sludge tank volume is carried by COSCO SAO PAULO with $23.6 \mathrm{~m} 3$.

2. The adequate capacity of oily bilge water volume receiver can be determined by the maximum oily bilge water received per day 442 $\mathrm{m} 3$. Average oily bilge water volume per day is $201.65 \mathrm{~m} 3$ while the minimum is $42.36 \mathrm{~m} 3$.

3. The adequate capacity of blackwater receiver can be determined from its maximum blackwater volume discharged per day which is $6.15 \mathrm{~m} 3$. The average of blackwater volume discharged is $3.37 \mathrm{~m} 3$ while the minimum is $1.23 \mathrm{~m} 3$.
4. The adequate capacity of greywater treatment receiver can be determined by the maximum volume of greywater discharge per day which is $16.9 \mathrm{~m} 3$. The average of greywater volume discharged per day is $9.27 \mathrm{~m} 3$ while the minimum is $3.38 \mathrm{~m} 3$.

5. The design of port-based discharge water treatment is choosing the simplest while combining four treatments on the first step of treatment. Sludge is treated by centrifugation method, oily sludge is treated by ultrafiltration and reverse osmosis, greywater is treated by Membrane Bioreactor (MBR) and blackwater is treated by SSS (Source Separation Sanitation).

6. The estimated initial cost for the plant can be reviewed from two categories: transportation initial cost and water treatment plant initial cost. The total transportation (from ship to WTP) initial cost is estimated around IDR $5,856,040,711.2$ and the total water treatment plant initial cost is estimated to be around IDR $16,631,046,165$ resulting in a total of IDR $22,487,086,876$. The payback period (PBP) of this plant is 4 years. 


\section{REFERENCES}

[1]. PT. TPS. (2017). Data Asset. Surabaya: PT. TPS

[2]. Barisci, S., \& Turkay, O. (2016). Domestic Greywater Treatment by Electrocoagulation Using Hybrid Electrode Combinations. Journal of Water Process Engineering 10, 56-66.

[3]. Islam, B. (2015). Petroleum Sludge, Its Treatment, and Disposal: A Review. International Journal of Chemical Sciences, 15841602.

[4]. Oarga-Mulec, A., Jenssen, P. D., Klemencic, A. K., Ursic, M., \& Bulc, T. G. (2017). Zero-Discharge Solution for Blackwater Treatment at Remote Tourist Facilities. Journal of Cleaner Production, 798-805.
[5]. National Development Planning Agency (BAPPENAS). (2013 July 23). Brief Perspective on National and International Shipping Network in Indonesia. Retrieved from UNESCAP: https://www.unescap.org/sites/default/files/0.Indonesia.pdf

[6]. Ashok, S., Kumar, T., \& Bhalla, K. (2018). Integrated Greywater Management Systems: A Design Proposal for Efficient and Decentralised Greywater Sewage Treatment. 25th CIRP Life Cycle Engineering (LCE) Conference (pp. 609-614). Copenhagen: Elsevier. 